\title{
Development of Web-Based e-Discipline System: A Case Study for the Kingdom of Saudi Arabia
}

\author{
Adnan Mustafa AlBar and Md. Rakibul Hoque
}

\begin{abstract}
Saudi Arabia applauds education because of its critical importance in developing the country's human potential. In the 21 st century, private education facilities have opened all over the Kingdom. Education is a central aspect for the development and training of family and community life. Parents and teachers are deeply involved in their children's and student's education, respectively. Currently, the continuous involvement of technology in the education system promises to build an advanced education system by using all kinds of information and communication technology (ICT) resources. This paper highlights the need for close relations between administrators, teachers, and students. Concerned with this issue, this paper aims to provide a much needed web-based eDiscipline application system that controls and monitors the classroom environment using high technology and trained teachers. The development of an e-Discipline web-based application is based on three-tier system architecture. In this paper, we present a prototype of an e-Discipline application environment to be operated by the Ministry of Higher Education, which will supervise and train the teachers and administrative staff.
\end{abstract}

Index Terms-Education system, e-discipline, web-based application.

\section{INTRODUCTION}

The Kingdom of Saudi Arabia was founded in 1932; it was a time when education was not accessible to everyone and limited to individualized instructions at religious schools in mosques in urban areas. These schools were taught Islamic law and basic literacy skills. By the end of the century, Saudi Arabia had a well-known nationwide educational system providing free training and education starting from pre-school up to the university level to all Saudi citizens [1]. While the study of Islam remains at its core, the modern Saudi educational system provides quality instruction in diverse fields of modern and traditional arts and sciences. This diversity helps to meet the Kingdom's growing capability and educational environment with other highly developed countries.

Today, Saudi Arabia's nationwide public educational system comprises twenty eight (28) universities, more than 24,000 schools, and a large number of colleges and other educational and training institutions [2]. Open to every citizen, the system provides students with free education, books and health services. A measure of the government's

Manuscript received May 3, 2015; revised August 4, 2015

Adnan Mustafa AlBar is with the Information Systems Department, King Abdulaziz University, Jeddah 21589, Saudi Arabia (e-mail: ambar@kau.edu.sa).

Md. Rakibul Hoque is with the Department of Management Information Systems, University of Dhaka, Dhaka-1000, Bangladesh (e-mail: rakibul@du.ac.bd). substantial commitment to this sector is the allocation of over $25 \%$ of the annual state budget for education, including vocational training. Education is a central aspect of family and community life. Parents are deeply involved in their children's education, and the close links between home and school serve to reinforce the structure of the community and the nation.

General education in the Kingdom consists of kindergarten, six years of primary school, and three years each of intermediate and high school [3]. The Ministry of Education sets overall standards for the country's educational system and also oversees special education for the handicapped. Early in 2003, the General Presidency for Girls' Education was dissolved, and its functions were taken over by the Ministry to administer the girls' schools and colleges, supervise kindergartens and nursery schools, and sponsor literacy programs for females. The first government school for girls was built in 1964; by the end of the 1990s, there were girls' schools in every part of the Kingdom. Of the nearly 5 million students enrolled in Saudi schools for the academic year 2003-2004, about half were female [4]. The five universities accept both male and female students - King Saud, King Abdulaziz, King Faisal, Imam Muhammad bin Saud, and Umm Al-Qura and the numerous colleges set up exclusively for women. The dramatic quantitative growth of the educational system since the introduction of the First Development Plan in 1970 has been more than matched by an improvement in the quality of education. One measure of this emphasis is that while the number of students in the educational system increased sixfold between the 1970s and the 1990s, the number of fulltime teachers grew more than nine-fold. The Kingdom's ratio of 15 students to every teacher is one of the lowest in the world.

The government, however, continues to work to improve educational standards. This has been achieved by raising the quality of teacher training programs, improving standards for the evaluation of students, and increasing the use of educational technology. One aspect of this is the introduction of computer science at the secondary level. In addition, the educational system has also been enhanced by introducing different types of ICT based administration such as e-Discipline. In e-Discipline systems, the teachers not only can record misconduct cases among their students but they will be given opportunity for improving themselves through counseling and community service programs. Moreover, parents can check their children records of academic achievement, co-curricular, discipline and presence in the school for taking a preventive action before being suspended. Notification via e-mail and Short Messaging System will be automatically received when their children are involved in any activity of wrongdoings [5]. 


\section{SCHOOL DisCIPLINE}

School discipline depends on a system of rules, punishments, and behavioral strategies appropriate to the regulation of children and the maintenance of order in schools. Its aim is to control students' actions and behavior. An obedient student is in compliance with the school rules and codes of conduct. These rules may, for example, define the expected standards of clothing, timekeeping, social behavior, and work ethic. The term discipline is also applied to the punishment that is the consequence of breaking the rules. The aim of discipline is to set limits restricting certain behaviors that are seen as harmful.

Throughout the history of education, the most common means of maintaining discipline in schools has been corporal punishment. While a child was in school, a teacher was expected to act as a substitute parent, with many forms of parental discipline or rewards open to them. This often meant that students were commonly chastised with a birch, cane, paddle, or strap if they did something wrong. Detention is another most common punishment in schools in the United States, Britain, Ireland, Singapore, Canada, Australia, and some other countries. It requires the pupil to go to a certain area of the school during a specified time on a school day (either break or after school), but it also may require a pupil to attend school at a certain time on a nonschool day, for example, "Saturday detention" at some US and UK schools. In UK schools, for offenses too serious for a normal detention but not serious enough for a detention requiring the pupil to return to school at a certain time on a non-school day, a detention can require a pupil to return to school one to two hours after school ends on a school day, for example, "Friday Night Detention." Suspension or temporary exclusion is a mandatory leave assigned to a student as a form of punishment that can last anywhere from one day to several weeks, during which time the student is not allowed to attend regular lessons [6]. In some U.S. and Canadian schools, there are two types of suspension: inschool suspension (ISS) and out-of-school suspension (OSS). ISS requires the student to report to school as normal but sit in a special room all day. OSS bars the student from being on school grounds. In some UK schools, there is reverse suspension as well as normal suspension. A suspended pupil is sent home for a set period of time. A pupil who is reverse suspended is required to be at school during the holidays.

Exclusion, expulsion, withdrawal, or permanent exclusion is the removal of a student permanently from the school. This is the ultimate last resort, when all other methods of discipline have failed [7]. However, in extreme situations, it may also be used for a single offense. Some education authorities have a nominated school in which all excluded students are collected; the school typically has a much higher staffing level than mainstream schools. In some U.S. public schools, expulsions and exclusions are so serious that they require an appearance before a board of education. In the UK, head teachers may make the decision to exclude, but the student's parents have the right of appeal to the local education authority. This has proved controversial in cases where the head teacher's decision has been overturned (and his or her authority thereby undermined), and there are proposals to abolish the right of appeal. Expulsion from a private school is a more straightforward matter, since the school can merely terminate its contract with the parents if the pupil does not have siblings in the same school.

\section{PRoposed E-Discipline WeB-BASED SyStEM: TOWARDS HIGH QUALITY SECONDARY SCHOOL SYSTEM IN KSA}

E-Discipline systems increase the efficiency of managing students' electronic records, to reduce the burden of teachers' works as well as to be a best tool in assisting the detection and prevention of discipline problems [5]. The eDiscipline project is in line with the implementation of the King Abdullah Project for General Education Development, the Kingdom of Saudi Arabia Tatweer project. In the spirit of the Tatweer project, this project aims to provide a much needed information system and ICT technology in creating a high-tech classroom environment and trained teachers to handle classes in a high-tech style. The project also aims at helping the Kingdom keep pace with scientific and technological development and is devised to benefit from successful experiments in countries such as Malaysia and the United States.

The Fig. 1 shows the client-server three-tier architecture for e-Discipline project. The e-Discipline project will be built based on web technology with three-tier system architecture. In this architecture, the client will only be responsible for the user-interface applications and implement certain simple logic processing, such as input validation. The basic application logic tasks will be done in the second tier vis-à-vis the application services layer. The third layer of the architecture is the database server layer, which helps to organize and manage data and information for later retrieval and updating. Physically, in this architecture, the client layer is linked to the server layer through a local area network (LAN) or a wide area network (WAN). The client application is designed to serve many types of client interfaces.

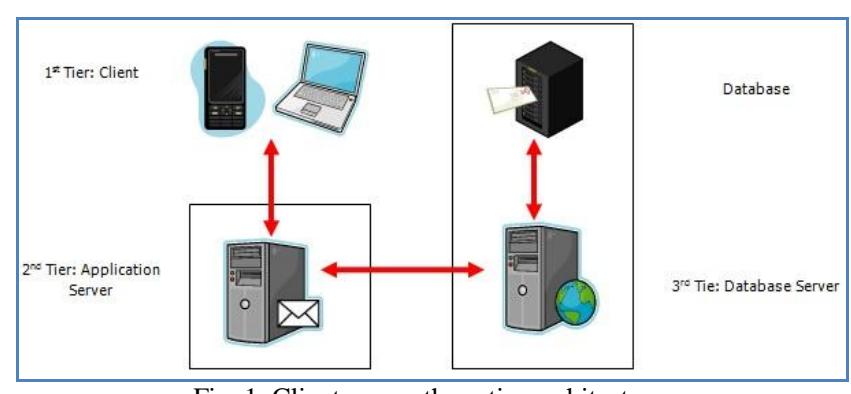

Fig. 1. Client-server three-tier architecture.

\section{A. System Design of e-Discipline}

In designing the system, the data and database are the most important components. Data are facts about things, people, entities, or events, whereas the database is a collection of related data shared by several categories of users to fulfill many organizational requirements. The database is a part an information system. Information systems involve the activities of collecting, keeping, retrieving, processing, and managing data. A database management system (DBMS) is application software that enables users to create, update, alter, maintain, and manage data and provides controlled access to the required data and 
information. Data on students' disciplinary cases are stored based on unique code [8].

\section{B. Requirements for Integrating a Web-Based DBMS for e-Discipline}

The e-Discipline system is based on three-tier architecture. A client is accountable only at the client interface and operates on several simple logical processes, such as input validation. The application for logical processes is located at a different tier. Physically, this architecture is connected to a client and database server through a local area network (LAN) or a wide area network (WAN). The advantages of three-tier architecture are maintenance for the application is centralized with the transmission of logical tasks to many end users in a typical service application, the addition and modification facility contributes to the ease of modifying and replacing information without affecting other tiers, the additional balancing is done easily by segregating logical tasks from its database function.

It is a web environment by which the web browser will act as a client, and the web server will act as the application server. Furthermore the architecture can be increased to nine tiers, which makes the architecture more flexible [9]. For example, the middle tier can be clustered into two tiers, with one tier for web service and another two tiers for application service. The advantages of a Web-Based DBMS for eDiscipline are Graphical Interface, Multi-platform independent, Network access transparency, Innovation.

\section{Approaches for Integrating Web-Based DBMS for e- Discipline}

In this section, a student's disciplinary database will be integrated into the web environment as shown below :

1) PHP (Preprocessor Hypertext) $\rightarrow$ the script language

2) MySql $\rightarrow$ the database application

3) Apache $\rightarrow$ the web browser

The software applications listed above are all freeware. It involves a pre-hypertext proccessor (PHP) implementation in the three-tier architecture [10].

\section{Overall Architecture of e-Discipline}

The modules in e-Discipline system use object-oriented software and tools with optimum security assurance. On the other hand, the database access is done either through the Internet or an intranet.

\section{E. Work Flow of the e-Discipline System}

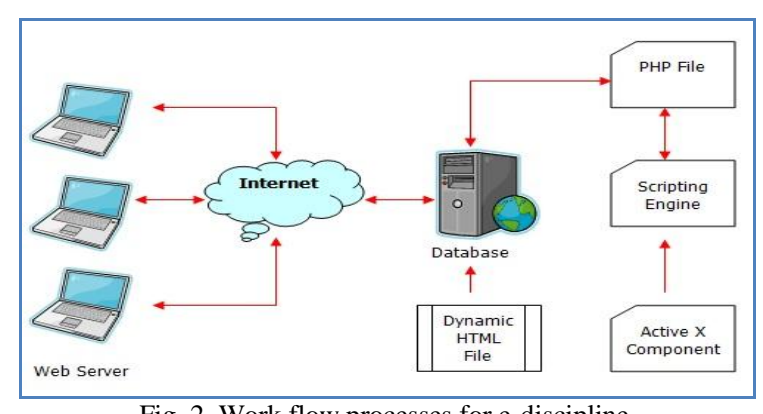

Fig. 2. Work flow processes for e-discipline.

The process and work flow for the e-Discipline system, which is to be developed, is shown in Fig. 2. The procedures to charge or grant any punishment to a student depend upon the attendance input entered through the system, which is validated by the student.The membes of the attendance committee include a discipline secretary, the principal or GPK HEM/supervisor, and a counseling Teacher. The eDiscipline system will issue printing or updating of a student's attendance records automatically.

\section{F. Web Server Environment for the e-Discipline System}

The use of open-source software tools can reduce cost and provide flexibility and easy maintenance. The web browser software is Apache, and web page development and processing engine uses PHP scripting language, while the web database is MySql. Student misconduct is measured by school as Verbal warning (score 1-19), First disciplinary warning (20-30 marks), Second disciplinary warning (3040 marks), Suspension (60-70 marks), Discipline last warning (80-90 marks), Expulsion (> 100 points)

A charity or intervention process is a way to redeem all the wrongs committed by a student; the process involves positive values that can reduce demerit points. It is also records the humanitarian work done by students when they are given a first disciplinary warning (20-30 marks). The eDiscipline system will provide a message to the school counselor for counseling activities, and the students will carry out charity works. All of these activities will be recorded through the system so that the changes in students' behavior can be documented. All this information will be stored in a student report card. Once the students get credit as a disciplinary level, then a warning letter will be generated automatically through the system to inform the school management, which has the authority to pass sentences toward the students.

A meeting will be held to discuss the results of actions toward the students who commit offenses, which are measured according to their degree of seriousness. A copy of reports will be sent to parents for reference and to notify them of any pending action and to explain the appeal process and defense. Parents who care for their children and express their concern can meet the principal/secretary of the discipline system and get more information about the student's conduct and possible discipline measures. The process of meeting with the parents is also recorded in the student report cards.

Thus, this e-Discipline system is a computer system that allows the group to obtain disciplinary information efficiently and quickly. All information entered by the teachers in each school will continue to be available and accessible by the Ministry of Education for further actions.

\section{THE PROPOSED DEVELOPMENT OF THE E-DISCIPLINE SYSTEM}

The Fig. 3 shows the main menu of e-Discipline systems. The proposed modules in the e-Discipline system that will be developed in the open-source platform are as follows:

1) System Access Module - This module is important in web system development. An access control list (ACL) is controlled automatically with the unique design of passwords. It also provides users with public access through a simple query system. Access is through a web page. Public and client access is "selective," whereby the level or access category will be determined by the security password provided. 
2) Data Entry Module - This module allows users, such as teachers, coordinators, and discipline teachers to have access through the web main server (eDisciplineDBWEB) to enter data or to record student's disciplinary information.

3) Discipline Record Module - This module allows the system administrator to update related information on previous or new discipline lists. The update process includes the functions of add, delete, and modify to amend the disciplinary records from the appropriate committee meetings. The module also serves as a room to announce and publish any counseling activities.

4) Update Module - This module allows users to update information that is already stored in the main database (e-DisciplineDBUtama), with input given by the end user. The update process for all input data is either done in "one lump sum" or according to detail clustering by the end user.

5) Analysis \& Report Generation Module - This module serves as a tool to generate reports and analyses based on the merit system. The standard value in this merit system is arbitrary and can be set by the Saudi Education Ministry. Warning letters and data analysis will be generated automatically according to the category needed by the user, subject to access control to the discipline database.

6) Information Transfer \& Backup Module - This module allows user to transfer information from the eDisciplineDBUtama database to the eDisciplineDBWEB database for public or client access in the web server environment.

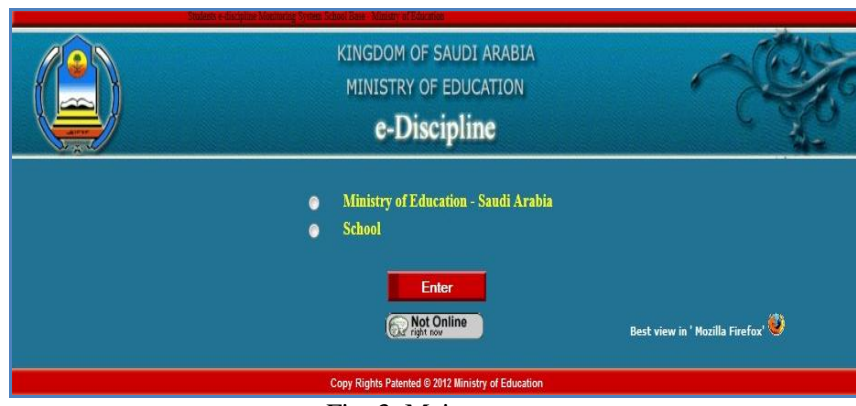

Fig. 3. Main menu.

\section{CONCLUSION}

In conclusion, all three main modules have been developed at the prototype level, and testing of these modules is still an ongoing process. The prototypes will be integrated with the subsequent development of the remaining modules. In summary, educating society is a good endeavor and will be granted a big "return" by Almighty Allah. Thus, parents along with school management should play an important role in educating their descendants. The human touch should be included with the three main education mechanisms, which are auditory, visual, and kinestatic. They should be imposed on our young, or even on the mature generation, in order to develop "bright and shiny" human capital. The system and technology are just a "backbone" and "catalyst" to hasten and smooth the process of human capital development. It is hoped that the proposed system will be used by all parties to handle student disciplinary problems before more severe discipline issues are triggered.

\section{ACKNOWLEDGMENT}

The research work was supported by King Abdulaziz University research fund through Deanship of Scientific Research. The authors are very thankful to them and appreciate their continuous support.

\section{REFERENCES}

[1] M. Alrobaee et al., The Quantitative Accomplishments of Selected Aspects of the Educational Process 1960-1990 with an Examination of the Reading Curricula Concepts in Saudi Arabia, West Virginia University, 2004.

[2] J. Yussra, "Understanding private higher education in Saudi Arabiaemergence, development and perceptions," $\mathrm{PhD}$ dissertation, Institute of Education, University of London, 2012.

[3] A. A. Abdulrahman, "An evaluation of the sixth grade English language textbook for Saudi boys' schools," PhD dissertation, King Saud University, 2008.

[4] A. A. Latifah, "The effectiveness of using cooperative learning method on ESL reading comprehension performance, students' attitudes toward CL, and students' motivation toward reading of secondary stage in Saudi public girls' schools," Student dissertation, West Virginia University, 2008.

[5] S. M. Idzwan, M. M. R. Rahimi, R. A. Yaacob, and Z. Yusoff, "Managing students' electronic disciplinary records via E-merit web content management system," in Proc. 2011 IEEE Conference on Open Systems (ICOS), 2011, pp. 261-266.

[6] D. Morgan, "Best practices for successful in school suspension programs," Master thesis, St. John Fisher College, 2013.

[7] T. A. Mohammed and A. A. Lukman, "Management of disciplinary problems in secondary schools: Jalingo metropolis in focus," Global Journal of Human-Social Science Research, vol. 13, no. 14, 2014.

[8] M. M. Saman and M. Y. M., Bakar, "SmartChecker: Real time monitoring and tracking students class attendance using wireless PDA," in Proc. Mobile Online Learning Technology and Application, 2007, pp. 86-93.

[9] World Data on Education Project, UNESCO IBE, 2006-2007.

[10] World Bank, "The road not travelled: Education reform in the Middle East and North Africa," World Bank 2008 Education Flagship Report, 2008, p. 105.

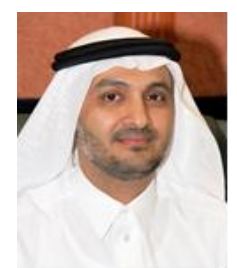

Adnan Mustafa AlBar is an assistant professor at the Department of Information Systems, Faculty of Computing and Information Technology, King Abdulaziz University, Saudi Arabia. He is an active member of the department where he was a member of the committee who prepared the executive master degree and also participate in reviewing the $\mathrm{IS} \mathrm{PhD}$ program. He teaches courses related enterprise systems, ERP and BPM. He was the first IS department chairman, the first vice dean for Development of Student Affairs. Dr. Albar is a member of the SAP International Advisory Board for Academic and Education. He is the founder and managing director of IT Expert House where he leads a team of consultants to provide consultation for the private sectors. Dr. Adnan is a senior member of IEEE, a member of $\mathrm{ACM}$ and ISACA. His main research is in enterprise information systems, enterprise architecture, business process management and technology adoption at the organizational level.

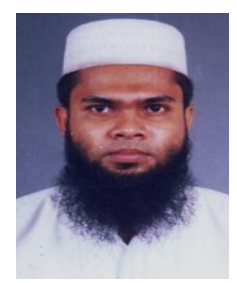

Md. Rakibul Hoque is an assistant professor of management information systems at University of Dhaka, Bangladesh. His research interests include technology adoption, e-Health and ICT4D. Mr. Hoque has published number of research articles in peer-reviewed academic journals, and has presented papers in international conferences. He had the opportunity to work in a number of research projects in Bangladesh, China, Australia and Saudi Arabia. Mr. Rakibul is the member of Association for Information Systems (AIS), UNESCO Open Educational Resources Community, IEEE, Internet Society and ISACA. He is currently pursuing his $\mathrm{PhD}$ at Huazhong University of Science and Technology, China. 